\title{
Volatile Products Formed from L-Cysteine and Propanal Thermally Treated in Triglyceride-Water Systems
}

\author{
Joji OKuMURA \\ Kawasaki Research Center, T. Hasegawa Co., Ltd., 335 Kariyado, \\ Nakahara-ku, Kawasaki 211, Japan
}

Received November 7, 1990

\begin{abstract}
Volatile compounds formed from model systems of equimolecular amounts of L-cysteine and propanal reacted at $110^{\circ} \mathrm{C}$ for $3 \mathrm{hr}$ in triglyceride, deionized and distilled water, or their mixtures were investigated. The volatiles were isolated by ether extraction of vacuum steam-distillates of reaction mixtures and analyzed by gas chromatography and coupled gas chromatography-mass spectrometry. Qualitative and quantitative differences in volatiles formed in the systems were observed. The amounts of total volatiles were highly varied according to the composition of the reaction medium. 2-Ethylthiazolidine was the most predominant in the triglyceride system. 2-Methyl-2-pentenal was a secondary dominating product in the triglyceride system and the most predominant in the triglyceride-water and water systems. The amounts of other volatile compounds including a novel compound, 2-ethylthiazolidino[3,4-b] thiazolidine (I), were also changed according to the systems. The highest production of $I$ was observed in the triglyceride-water $(75: 25)$ system.
\end{abstract}

Numerous flavor components have been found in many processed foods. It has been well-known that most of these flavor compounds can be produced by the Maillard reaction. ${ }^{1,2)}$ Many studies have been done on the formation of volatile compounds from the reaction of amino acids with sugars and carbonyls. ${ }^{3-8)}$ It has been observed that flavor qualities formed by these reactions have been changed by differences of solvent systems. In producing 'processed flavors,' water, oil and fat, or their mixture are used as reaction media for various application. However, there are few investigations on the effects of the difference of reaction medium on volatiles formed by the amino-carbonyl reaction. I had reported that different solvent systems such as water, glycerine, or triglyceride had large effects on the quality and quantity of volatile compounds formed from thermally treated Lcysteine with dihydroxyacetone. ${ }^{9)}$

Aliphatic aldehydes themselves contribute to flavors of many kinds of foods, and further relate to flavor formation by reacting with other compounds. Suyama and Adachi ${ }^{10}$ studied the formation of pyridines from the reaction of alkanals with amino acids. Zhang and $\mathrm{Ho}^{11)}$ reported the volatile compounds from thermal interaction of 2,4-decadienal with cysteine and glutathione in an aqueous medium. Several researchers examined reactions of aldehydes with hydrogen sulfide and ammonia, or ammonium sulfide, and characterized nitrogen- and sulfur-containing volatile compounds. ${ }^{12-17)}$ Propanal has been identified in the volatiles of many kinds of food $^{18)}$ and also in the Maillard reaction products. ${ }^{19)} \mathrm{A}$ patent claims a method to prepare a simulated onion flavor by reacting propanal with sodium sulfide in water. ${ }^{20}$ Led $^{13)}$ showed that the reaction of propanal with $\mathrm{H}_{2} \mathrm{~S}$ and $\mathrm{NH}_{3}$ formed an onion-like odor and identified many sulfur-containing compounds.

In this study, thermal interaction between L-cysteine and propanal in triglyceride, water, or their mixtures was examined and qualitative and quantitative differences in volatiles were compared. As triglyceride, a saturated medium chain triglyceride was used for its high stability to heat and oxidation. 


\section{Materials and Methods}

Preparation of reaction mixtures. Equimolecular amounts of L-cysteine and propanal (each $0.14 \mathrm{~mol}$ ) were dispersed in $700 \mathrm{~g}$ of triglyceride : deionized and distilled water reaction medium at a $0,25,50,75$, and $100 \%$ water composition. As triglyceride, O.D.O. was used. O.D.O. is a medium chain triglyceride (fatty acid composition: octanoic acid $(75 \%)$ and decanoic acid $(25 \%)$ ) manufactured by Nisshin Oil Mills Ltd., Tokyo, Japan. These model systems were heated at $110^{\circ} \mathrm{C}$ for $3 \mathrm{hr}$ in an autoclave with stirring.

Isolation of volatiles. Two hundred grams of the heated model system were mixed with $1200 \mathrm{~g}$ of deionized and distilled water and an appropriate quantity of O.D.O. to adjust the oil content in the system. After further addition of $10 \mathrm{ml}$ of a diethyl ether solution of $n$-tetradecane $(2 \mathrm{mg} / \mathrm{ml})$ as an internal standard, the mixture was steam-distilled under reduced pressure $\left(30 \mathrm{mmHg} / 40^{\circ} \mathrm{C}\right)$. The distillate $(400 \mathrm{~g})$ condensed with cold water $\left(3^{\circ} \mathrm{C}\right)$ and two cold traps (dry ice-acetone and liquid nitrogen) was extracted three times with $40 \mathrm{ml}$ of diethyl ether after saturation with sodium chloride. The extract was dried over anhydrous $\mathrm{Na}_{2} \mathrm{SO}_{4}$ and then concentrated at $36-38^{\circ} \mathrm{C}$ under atmospheric pressure. The volatile reaction products in each resulting concentrate were analyzed and measured by gas chromatography (GC) and coupled gas chromatography-mass spectrometry (GC-MS):

$G C$ conditions. Gas chromatographic analyses were done on a Shimadzu GC-14A with a flame ionization detector (FID), a flame thermionic detector (FTD), and a flame photometric detector (FPD), fitted with a $0.25 \mathrm{~mm}$ i.d. $\times 60 \mathrm{~m}$ fused silica capillary column coated with PEG $20 \mathrm{M}$. The column temperature was programmed from 70 to $220^{\circ} \mathrm{C}$ at $3^{\circ} \mathrm{C} / \mathrm{min}$. The injection port and detector temperatures were kept at $250^{\circ} \mathrm{C}$. The nitrogen carrier gas flow was $1 \mathrm{ml} / \mathrm{min}$. Peak areas were integrated using a Shimadzu C-R3A Chromatopac integrator connected to the gas chromatograph.

Preparative $G C$. An unknown compound in the volatile reaction products was isolated by preparative $\mathrm{GC}$ under the same condition as described by Yajima et al. ${ }^{21)}$ except that a glass column packed with $10 \%$ Carbowax $20 \mathrm{M}$ on Chromosorb W ( $3 \mathrm{~mm}$ i.d. $\times 3 \mathrm{~m}$ ) was used and that column oven temperature was programmed from 80 to $220^{\circ} \mathrm{C}$ at $3^{\circ} \mathrm{C} / \mathrm{min}$.

Identification of compounds. Most of the individual compounds were identified by comparing and matching the mass spectra and GC retention times of compounds with those of authentic compounds. Nitrogen- or sulfurcontaining compounds were confirmed by FTD and FPD, respectively.

a) GC-MS analysis. A Hitachi Model M-80B mass spectrometer was used for mass spectral identification of the gas chromatographic components under the following conditions: column, fused silica capillary column $(0.25 \mathrm{~mm} \times 60 \mathrm{~m})$ coated with $\mathrm{PEG} 20 \mathrm{M}$; oven temperature, programmed from 60 to $210^{\circ} \mathrm{C}$ at $2^{\circ} \mathrm{C} / \mathrm{min}$; carrier gas, helium; ionizing voltage, $70 \mathrm{eV}$; accelerating voltage, $3000 \mathrm{~V}$; ion source temperature, $190^{\circ} \mathrm{C}$.

b) Nuclear magnetic resonance $(N M R)$ analysis. NMR spectra were taken at $90 \mathrm{MHz}$ in $\mathrm{CDCl}_{3}$ on a JEOL FX90A fourier transform NMR spectrometer. Chemical shifts were expressed in parts per million with tetramethylsilane as an internal standard.

c) Infrared (IR) analysis. IR spectra were recorded on a JASCO FT/IR-5000 infrared spectrometer.

Synthesis of 2-ethylthiazolidino[3,4-b] thiazolidine. This compound was synthesized by following a route similar to the proposed formation mechanism of 2-methylthiazolidino $[3,4-b]$ thiazolidine. ${ }^{22)}$ Cysteamine hydrochloride $(22.5 \mathrm{~g})$ was reacted with 2,5-dihydroxy-1,4dithiane $(15.2 \mathrm{~g})$ in a solution of $\mathrm{KOH}(7.9 \mathrm{~g})$ in methanol $(100 \mathrm{ml})$ at $65^{\circ} \mathrm{C}$ for $5 \mathrm{hr}$. After addition of propanal $(11.6 \mathrm{~g})$ to the reaction mixture, the reaction was further continued for $2 \mathrm{hr}$. The reaction mixture was extracted with diethyl ether and the ether extract was washed with brine then aqueous $\mathrm{NaHCO}_{3}$ solution, and dried over anhydrous $\mathrm{MgSO}_{4}$. After removal of ether, the residue was distilled to give 2-ethylthiazolidino $[3,4-b]$ thiazolidine $(8.0 \mathrm{~g}, 22.8 \%$ yield, bp $101-102^{\circ} \mathrm{C} / 3$ Torr). IR $v_{\max } \mathrm{cm}^{-1}: 2950,1440$, 1295, 1200, 1075, 913, 750, 656. MS m/z: $177(9 \%), 176$ (11), $175\left(100, \mathrm{M}^{+}\right), 146(68), 129(61), 128(48), 114(77)$, $101(30), 86(77), 68(36), 61(42), 59(57), 54(42), 45(71)$, $41(52), 28(49), 27(46), \mathrm{NMR} \delta_{\mathrm{H}}\left(\mathrm{CDCl}_{3}\right): 0.95(3 \mathrm{H}, \mathrm{t}$, $J=7.1 \mathrm{~Hz}), 1.39-1.83(2 \mathrm{H}, \mathrm{m}), 2.953 .57(6 \mathrm{H}, \mathrm{m}), 4.03(1 \mathrm{H}$, dd, $J=5.05,7.70 \mathrm{~Hz}), 4.99(\mathrm{lH}, \mathrm{dd}, J=5.50,3.41 \mathrm{~Hz}) . \delta_{\mathrm{C}}$ $\left(\mathrm{CDCl}_{3}\right): 10.79,31.16,36.47,55.21,71.41,74.72$.

\section{Results and Discussion}

Table I presents the results of sensory evaluation of the flavor qualities of reaction mixtures and the relative amounts of total volatiles that were obtained by heating L-cysteine with propanal at $110^{\circ} \mathrm{C}$ for $3 \mathrm{hr}$ in various reaction media composed of triglyceride and water. Sensory results indicated the higher triglyceride content systems gave stronger flavor and more aldehydic notes, and the lower triglyceride content systems gave more onion-like notes. The relative amounts of total volatiles changed greatly according to the composition of reaction medium. The maximum amount of volatiles was produced 

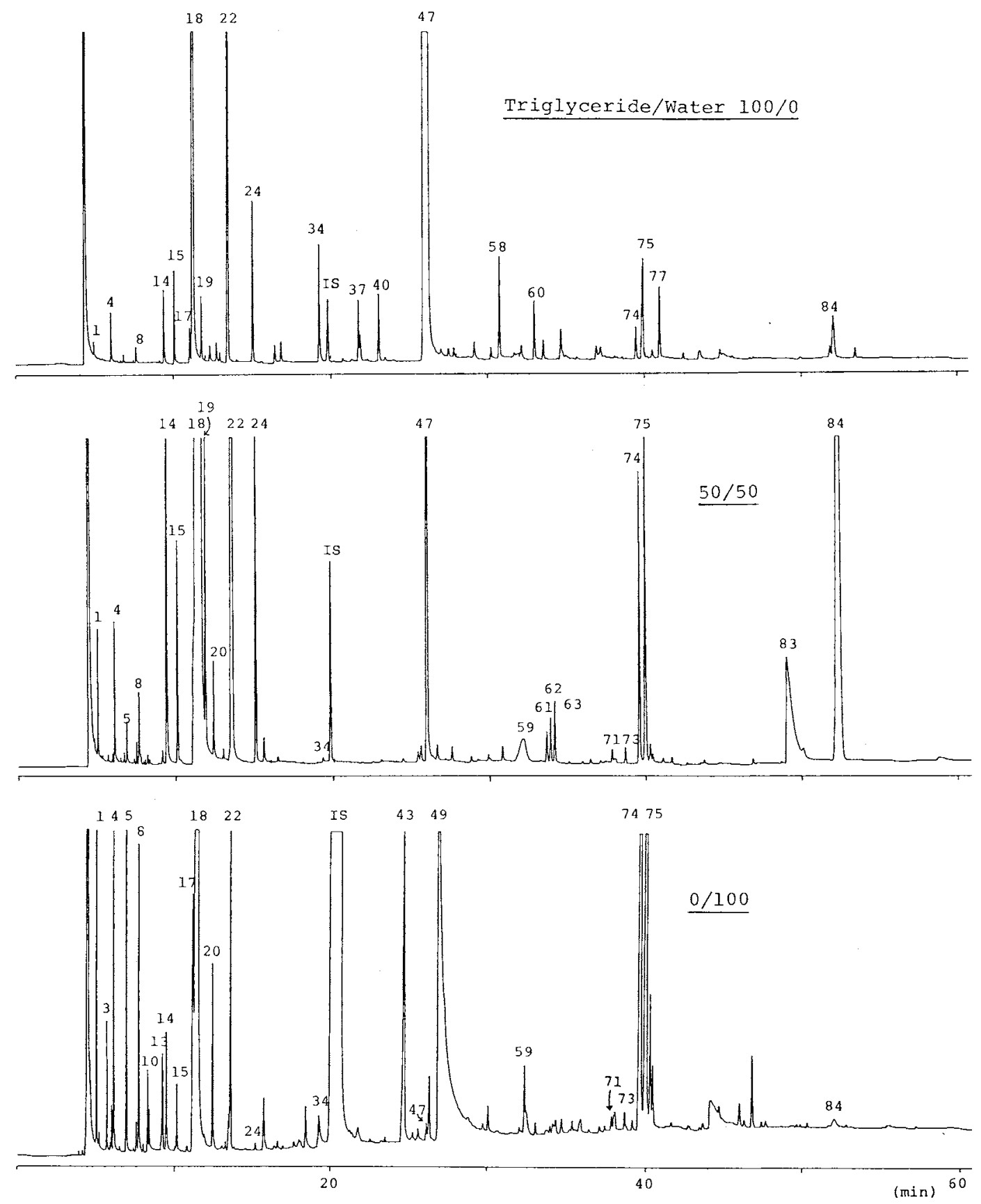

Fig. 1. Gas Chromatograms of Volatiles Formed in L-Cysteine-Propanal Model Systems Reacted in Triglyceride-Water Media.

$n$-Tetradecane was used as an internal standard (IS). Detector, FID.

in the $75 \%$ triglyceride system with a slight decrease in the $100 \%$ and $50 \%$ triglyceride systems, and further with rapid decline in the systems of lower triglyceride content. The relative amount of volatiles produced in the $100 \%$ water medium was only at about $1 / 380$ 
Table I. The Flavor Qualities of Reaction Mixtures and the Relative Amounts of Total Volatiles ObTained from l-Cysteine-Propanal Model Systems REACTED in TRIGlyCERIDE-WATER MEdia

\begin{tabular}{clc}
\hline Reaction medium & \multicolumn{1}{c}{ Flavor description of reaction mixture } & $\begin{array}{c}\text { Relative amount of } \\
\text { total volatiles }^{a}\end{array}$ \\
\hline $\begin{array}{c}\text { Triglyceride-Water }(\mathrm{w} / \mathrm{w}) \\
100: 0\end{array}$ & Green, aldehydic, metallic, vegetable-like & 369 \\
$75: 25$ & Aldehydic, beany, cooked vegetable like onion & 457 \\
$50: 50$ & Half-boiled onion & 349 \\
$25: 75$ & Vegetable, onion-like, somewhat sulfur note & 36 \\
$0: 100$ & Boiled and pickled onion, sulfury, somewhat roasted note & 1.2 \\
\hline
\end{tabular}

a Sum of peak area of each component/peak area of internal standard $\left(\mathrm{C}_{14} \mathrm{H}_{30}\right)$.

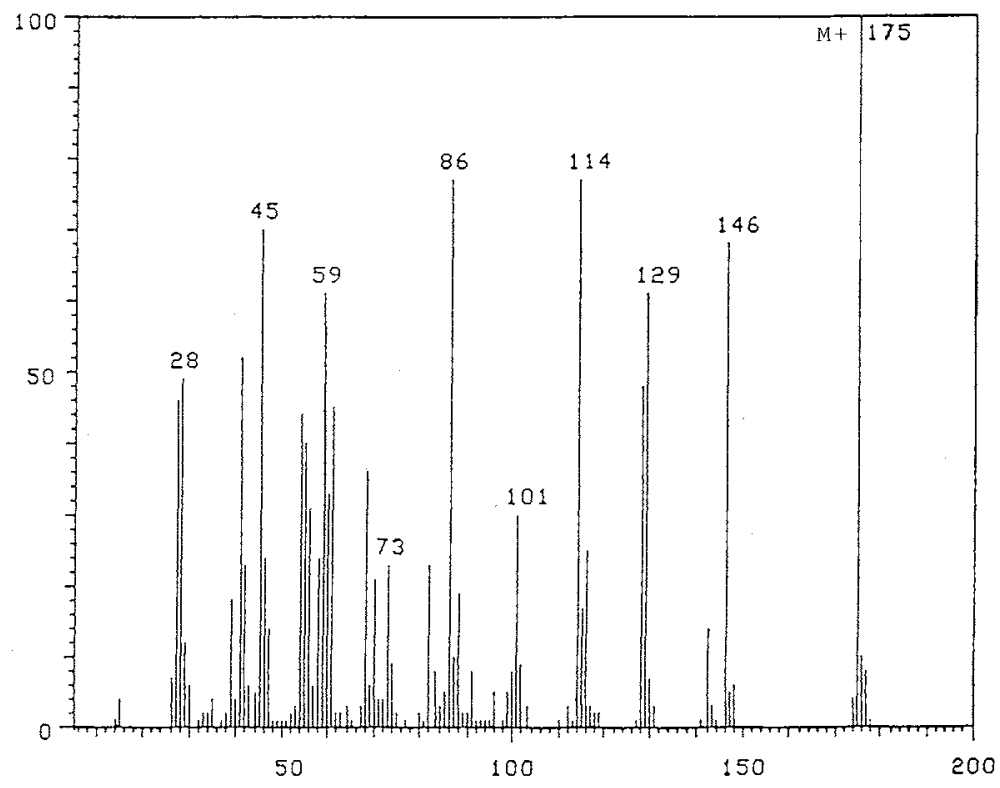

Fig. 2. Mass Spectrum of Peak No. 84.

of those in the $75 \%$ triglyceride system.

Figure 1 shows gas chromatograms recorded by FID of volatiles formed in L-cysteinepropanal model systems reacted at $110^{\circ} \mathrm{C}$ for $3 \mathrm{hr}$ in reaction media composed of triglyceride-water, $100: 0,50: 50$, and $0: 100$. It was shown that there were great differences in the profiles of volatile products.

Peak No. 84 could not be identified by the data of GC and GC-MS. This peak was trapped by preparative $\mathrm{GC}$, and investigated spectrometrically. Figures 2 and 3 show the MS and ${ }^{1} \mathrm{H}-\mathrm{NMR}$ spectrum of the trapped material. The molecular ion in MS appeared at $m / z 175(100 \%)$ and isotope ratios $(m / z 177$, $9 \%$ ) indicated two sulfur atoms in the molecule. Its molecular formula was estimated to be $\mathrm{C}_{7} \mathrm{H}_{13} \mathrm{NS}_{2}$. By comparing and matching the IR, ${ }^{1} \mathrm{H}-\mathrm{NMR}$, and mass spectra and $\mathrm{GC}$ retention time of the trapped material with those of authentic compound, the trapped material was identified as 2-ethylthiazolidino[3,4-b] thiazolidine (I). The IR spectra of peak No. 84 and synthesized $\mathbf{I}$ are shown in Fig. 4. The isolated and synthesized I had roasted leek, onion, and garlic-like odor. This compound has not been reported in natural foods nor in a model system. 


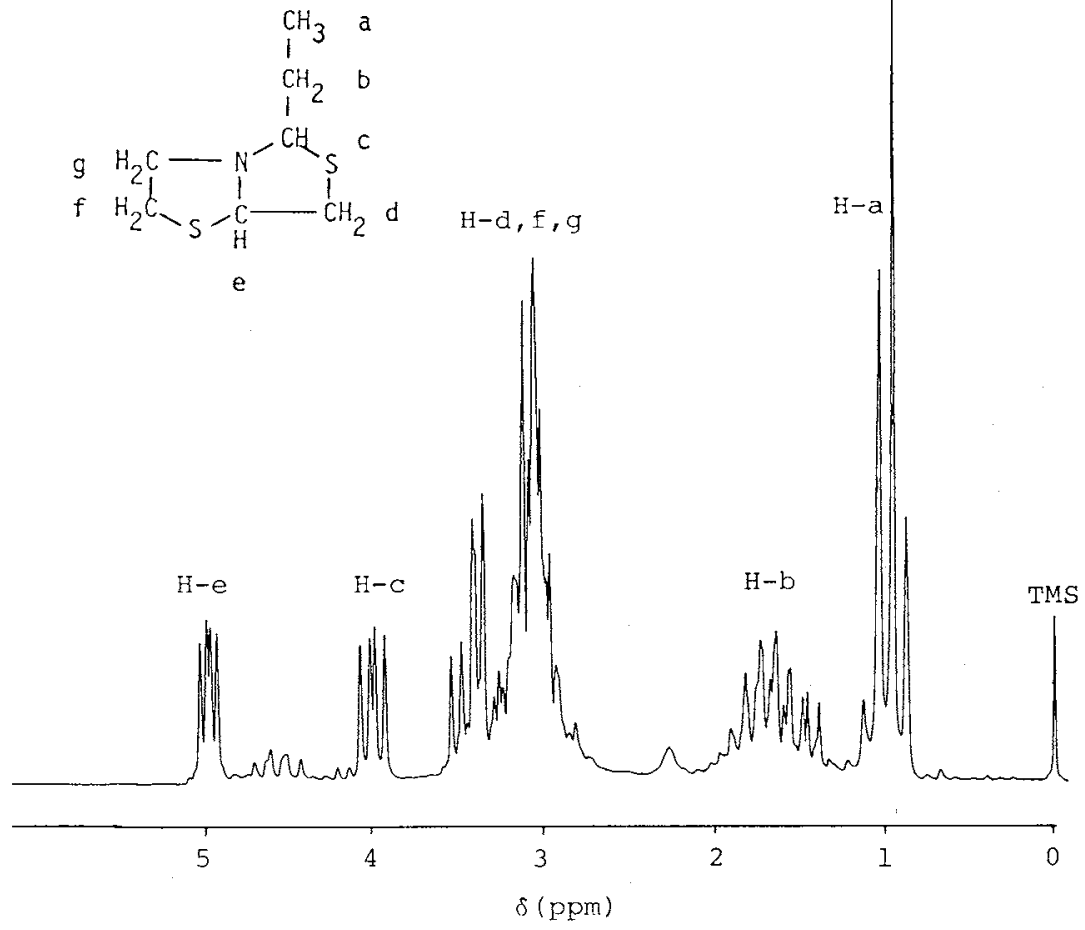

Fig. 3. ${ }^{1}$ H-NMR Spectrum of Peak No. 84.

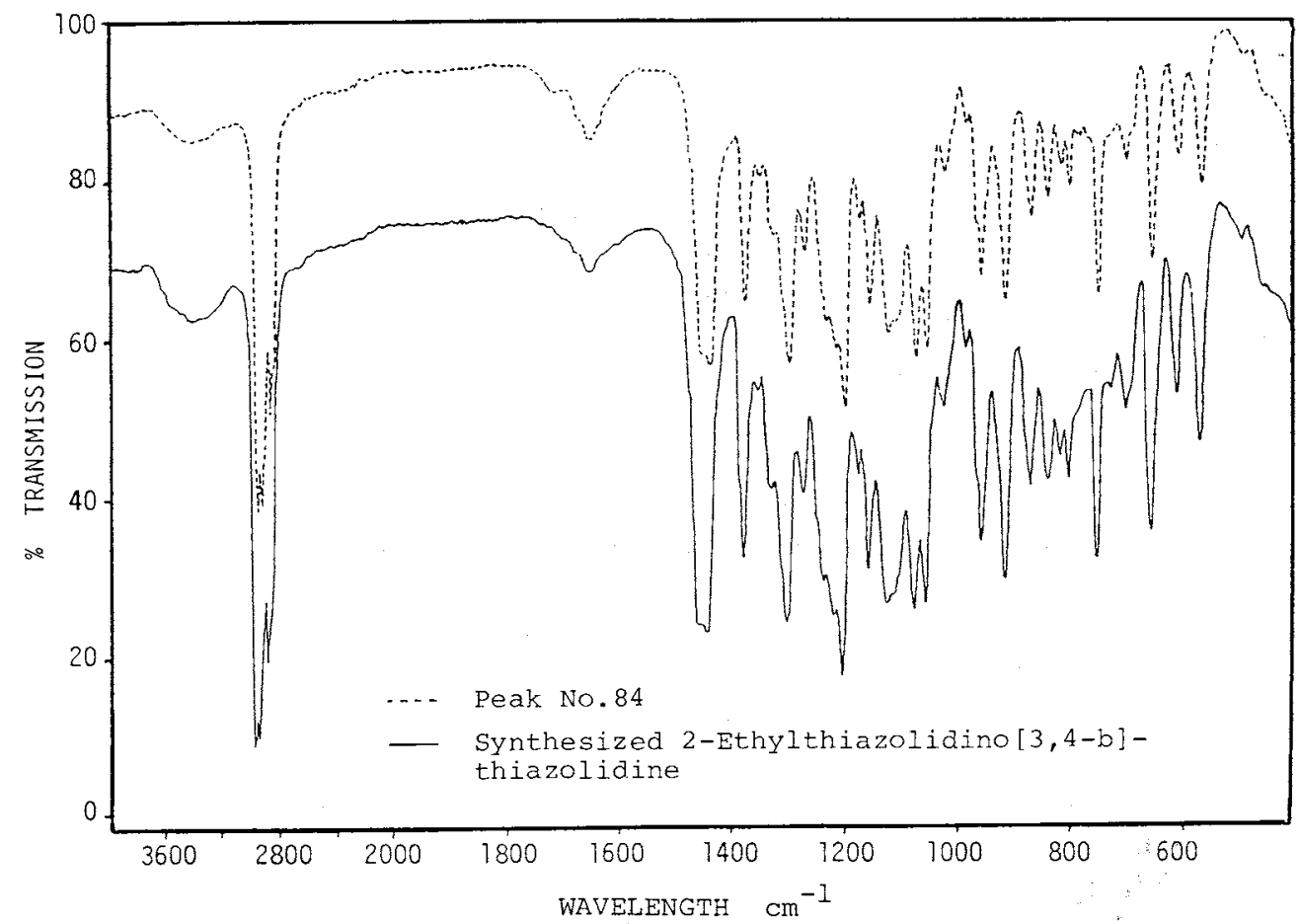

Fig. 4. IR Spectra of Peak No. 84 and Synthesized 2-Ethylthiazolidino[3,4-b]thiazolidine. 
Table II. The Relative Amounts ${ }^{a}$ of Volatile Compounds Obtained from l-Cysteine-Propanal Model Systems Reacted in Triglyceride-Water Media

\begin{tabular}{|c|c|c|c|c|c|c|}
\hline \multirow{2}{*}{ Compound } & \multirow{2}{*}{$\begin{array}{l}\text { Peak } \\
\text { No. }\end{array}$} & \multicolumn{5}{|c|}{ Triglyceride-water $(w / w)$} \\
\hline & & $100: 0$ & $75: 25$ & $50: 50$ & $25: 75$ & $0: 100$ \\
\hline Propanal & 1 & $+^{b}$ & + & + & + & + \\
\hline Ethyl acetate & 3 & $-{ }^{c}$ & - & - & - & + \\
\hline Ethanol & 4 & + & + & + & + & + \\
\hline 2-Pentanone & 5 & - & + & + & + & + \\
\hline Propanol & 8 & + & + & + & + & + \\
\hline 2,3-Pentanedione & 10 & - & - & + & + & + \\
\hline 3-Pentanol & 13 & - & - & + & + & + \\
\hline 2-Methyl-2-butenal & 14 & + & 1.8 & 2.4 & + & + \\
\hline 2-Methylthiophene & 15 & + & 2.8 & + & + & + \\
\hline 2-Methyl-2-pentenal & 18 & 64 & 242 & 297 & 20 & + \\
\hline 2,4-Diethyl-6-methyl-1,3,5-trioxane & 19 & + & 1.8 & 1.4 & + & + \\
\hline 2,5-Dimethylthiophene & 20 & + & + & + & + & + \\
\hline 2,4,6-Triethyl-1,3,5-trioxane & 22 & 12 & 22 & 18 & 10 & + \\
\hline 2,4-6-Triethyl-1,3,5-trioxane & 24 & 2.0 & 3.0 & 1.7 & + & + \\
\hline 2-Ethylthiazoline & 34 & 1.7 & + & + & + & + \\
\hline 2-Methylthiazolidine & 37 & + & + & - & - & - \\
\hline 2-Ethylthiazolidine & 47 & 272 & 118 & 5.8 & + & + \\
\hline Propionic acid & 49 & - & - & - & - & + \\
\hline 2,4-Dimethyl-2-buten-4-olide & 59 & - & 1.4 & + & + & + \\
\hline 3,5-Diethyl-1,2,4-trithiolane $(t)$ & 71 & - & + & + & + & + \\
\hline 3,5-Diethyl-1,2,4-trithiolane $(c)$ & 73 & - & + & + & + & + \\
\hline Unknown & 74 & + & 1.5 & 1.5 & + & + \\
\hline Unknown & 75 & 2.0 & 2.5 & 1.8 & + & + \\
\hline n-Octanoic acid & 83 & - & 3.6 & 2.9 & + & - \\
\hline 2-Ethylthiazolidino $[3,4-b]$ thiazolidine & 84 & 1.4 & 35 & 11 & 1.0 & + \\
\hline
\end{tabular}

Table II shows the relative amounts of volatile compounds obtained from L-cysteinepropanal model systems reacted in different triglyceride-water reaction media.

2-Ethylthiazolidine was the most predominant in the $100 \%$ triglyceride medium and occupied about $74 \%$ of total volatiles. 2Methyl-2-pentenal was a secondary dominating product in the $100 \%$ triglyceride medium and the most predominant in the triglyceridewater systems and the $100 \%$ water medium.

The amount of 2-ethylthiazolidine formed by heating L-cysteine with propanal was largest in the $100 \%$ triglyceride medium and decreased markedly as the water content in reaction medium was increased. On the other hand, 2-ethylthiazolidino $[3,4-b]$ thiazolidine (I) was produced at relative large amounts in the triglyceride-water $75: 25$ and $50: 50$ systems and at less amounts in the other systems. The maximum formation of this bicyclic thiazolidine I appears to occur in the system which contains a small amount of water in triglyceride. The maximum formation of 2-methyl-2pentenal was observed in the triglyceride/water $50 / 50$ system, and its amount was slightly decreased in the systems that contained more than $50 \%$ triglyceride and was sharply decreased in the less triglyceride content systems. The amount of 2-methyl-2-butenal also showed a similar tendency with that of 2-methyl-2-pentenal. The formation of 2,4,6triethyl- and 2,4-diethyl-6-methyl-1,3,5-trioxane was preferred in the triglyceride containing systems. The amount of 2-ethylthiazoline was larger in the $100 \%$ triglyceride medium than 
in the water containing systems.

As minor volatile components, 2-methylthiazolidine was detected in the triglyceride-water $100: 0$ and $75: 25$ systems. 3,5-Diethyl-1,2,4trithiolane was formed in the water containing systems. Propionic acid was detected only in the $100 \%$ water medium as a secondary abundant volatile compound.

The results indicate that the ratio of triglyceride and water content in reaction medium greatly affects the yield of total volatile products and qualitative and quantitative aspects of each volatile component. In the $100 \%$ triglyceride medium, propanal can be miscible in O.D.O. but cysteine only disperses. On the other hand, both of them can dissolve in water. Therefore, the variations observed among the volatiles produced in each system might be due to the difference of the existing state of cysteine and propanal in the reaction mixture. Furthermore, some researchers have observed the dilution or inhibition effect of higher water content on brown color formation in the Maillard reaction. ${ }^{23,24)}$ The concentrations of cysteine and propanal vary in aqueous phase of water containing systems in this study. This might affect a condensation step of the reactants. Arnoldi et al. ${ }^{25)}$ showed that cocoa butter had a strong effect on the rate of formation of the Strecker aldehydes from leucine and valine. Degradation of cysteine could be accelerated in the triglyceride-water systems. I $^{9)}$ showed that cysteine preferred degrading to sulfur-containing fragments and releasing $\mathrm{H}_{2} \mathrm{~S}$ in the reaction with dihydroxyacetone in the water system, and also showed that dehydration-type reactions like those producing pyrazines and thiazoles were favored in the triglyceride and glycerine systems. These various factors are presumed to affect the production of volatiles and the qualitative and quantitative differences of each volatile component from the reaction of cysteine with propanal in various triglyceride-water media.

The aldol condensation products of aliphatic aldehydes were identified in the model reaction systems composed of aldehydes and an amino acid or $\mathrm{H}_{2} \mathrm{~S}$ and $\mathrm{NH}_{3} \cdot{ }^{10,11,13,17,26)}$ Pokorný et $a .^{27)}$ described that the aldol condensation could be catalyzed by primary amino group of amino acids, and also found that nearly no aldolization took place in anhydrous mixtures and rapid reaction occurred in an aqueous medium. In this case, propanal might be catalyzed by the amino group of cysteine to form 2-methyl-2-pentenal in the water containing systems. 2-Methyl-2-butenal, the aldol condensation product of propanal and acetaldehyde, which is the degradation product of cysteine, might be formed in a similar way.

Many thiazoles and thiazolines are widely distributed in various foods and in model systems. ${ }^{4,5,18)}$ However, alkylthiazolidines were only identified in restricted model systems. 2-Methylthiazolidine was identified in the following model systems; glucose-, acetaldehyde- or glyoxal-cysteamine in aqueous solutions, ${ }^{28)}$ xylose-cysteine in tributyrin, ${ }^{29)}$ glucose-cysteine (no solvent), ${ }^{22)}$ cysteine or cystine in soybean oil ${ }^{30)}$ and pyrolysis of cysteine and cystine. ${ }^{31)}$ 2-Ethylthiazolidine was identified in an aqueous system of glucosecysteamine. ${ }^{28)}$ Fujimaki et al ${ }^{31)}$ postulated two pathways for the formation of 2-methylthiazolidine from pyrolysis of cysteine and cystine. The one was that acetaldehyde reacted with cysteamine originated from cysteine and cystine, and the other was that acetaldehyde reacted with cysteine to produce 2-methylthiazolidine-4-carboxylic acid which was decarboxylated to 2-methylthiazolidine. They mentioned that the former seemed to be more probable in their case. de Rijke et al. ${ }^{22)}$ also took the same postulated mechanism for 2-methylthiazolidine from cysteine reacted with glucose. However, 2-methylthiazolidine was identified in the triglyceride-water 100:0 and $75: 25$ systems only as minor product in this study. An earlier study on the reaction between cysteine and simple aldehydes showed the possibility of production of thiazolidine-4carboxylic acid derivatives. ${ }^{32)}$ Ledl $^{30)}$ reported the formation of thiazolidine by the thermal decomposition of thiazolidine-4-carboxylic acid in soybean oil. Consequently, 2-ethylthiazolidine identified in this study might be formed 
through the direct condensation of cysteine with propanal forming a thiazolidine ring and following decarboxylation.

2-Methylthiazolidino [3,4-b]thiazolidine (II) was identified as a minor product in pyrolysate of cysteine in soybean oil ${ }^{30)}$ and as a major product in the mixture of heated cysteine and glucose in a solid state under reduced pressure. ${ }^{22)}$ de Rijke et al. ${ }^{22)}$ postulated a possible mechanism on the formation of II by a two-step process which included the formation of 2-mercaptomethyl-thiazolidine (III) as a intermediate by condensation of cysteamine with mercaptoacetaldehyde, and further reaction of III with acetaldehyde to give II. In this study, if these decomposition products of cysteine were concerned in the formation of a bicyclic thiazolidine, II could be formed. However, II could not be identified in this study. Therefore, it is difficult to consider that $\mathbf{I}$ identified in this study could be formed from cysteamine, mercaptoacetaldehyde, and propanal in a two-step process similar to that postulated by de Rijke et al. ${ }^{22}$ Further investigation would be necessary to elucidate the formation pathway of $\mathbf{I}$.

In summary, it has been shown that the difference in the ratio of triglyceride to water in reaction medium affects the quality and quantity of volatile compounds produced in the reaction of cysteine with propanal. These results can be useful to produce simulated 'processed flavors' by the amino-carbonyl reactions, and also to elucidate the flavor formation in heated foods containing fatty oils such as meat, cacao, and coffee.

Acknowledgment. I thank Dr. T. Yanai for the MS analyses and Dr. A. Fujita for the NMR measurements.

\section{References}

1) R. F. Herrell, Dev. Food Sci., 3A, 399 (1982).

2) J. P. Danehy, Adv. Food Res, 30, 77 (1986).

3) J. E. Hodge, F. D. Mills and B. E. Fisher, Cereal Sci. Today, 17, 34 (1972).

4) G. Vernin, "Chemistry of Heterocyclic Compounds in Flavours and Aromas," Ellis Horwood Ltd., Chichester, England, 1982, pp. 72-207.

5) S. Fors, in "The Maillard Reaction in Foods and
Nutrition," ACS Symp. Ser. 215, ed. by G. R. Waller and M. S. Feather, American Chemical Society, Washington, D. C., 1983, pp. 185-286.

6) T. Shibamoto, in "Thermal Generation of Aromas," ACS Symp. Ser. 409, ed. by T. H. Parliment, R. J. McGorrin and C-T. Ho, American Chemical Society, Washington, D. C., 1989, pp. 134-142.

7) W. Baltes, J. Kunert-Kirchhoff and G. Reese, in "Thermal Generation of Aromas," ACS Symp. Ser. 409, 1989, pp. 143-155.

8) R. Tressl, B. Helak, N. Martin and E. Kersten, in "Thermal Generation of Aromas," ACS, Symp. Ser. 409, 1989, pp. 156-171.

9) J. Okumura, T. Yanai, I. Yajima, K. Hayashi, Agric. Biol. Chem., 54, 1631 (1990).

10) K. Suyama and S. Adachi, J. Agric. Food Chem., 28, 546 (1980).

11) Y. Zhang and C.-T. Ho, J. Agric. Food Chem., 37, 1016 (1989).

12) M. Boelens, L. M. van der Linde, P. J. de Valois, H. M. van Dort and H. J. Takken, J. Agric. Food Chem., 22, 1071 (1974).

13) F. Led1, Z. Lebensm. Unters.-Forsch., 157, 28 (1975).

14) H. J. Takken, L. M. van der Linde, P. J. de Valois, H. M. van Dort and M. Boelens, in "Phenolic, Sulfur and Nitrogen Compounds in Food Flavors," ACS Symp. Ser. 26, ed. by G. Charalambous and I. Katz, American Chemical Society, Washington, D. C., 1976, pp. 114-121.

15) T. Kawai and Y. Ishida, J. Agric. Food Chem., 37, 1026 (1989).

16) C.-K. Shu, B. D. Mookherjee, H. A. Bondarovich and M. L. Hagedorn, J. Agric. Food Chem., 33, 130 (1985).

17) S.-S. Hwang, J. T. Carlin, Y. Bao, G. J. Hartman, and C.-T. Ho, J. Agric. Food Chem., 34, 538 (1986).

18) H. Maarse and C. A. Visscher, Eds., "Volatile Compounds in Food, Qualitative and Quantitative Data," Vols. I-III, TNO-CIVO Food Analysis Institute, Zeist, The Netherlands, 1989.

19) L. W. Rooney, A. Salem and J. A. Johnson, Cereal Chem., 44, 539 (1967).

20) C. Wiener, U. S. Patent 3,650,771 (May 21, 1972).

21) I. Yajima, T. Yanai, M. Nakamura, H. Sakakibara and K. Hayashi, Agric. Biol. Chem., 48, 849 (1984).

22) D. de Rijke, J. M. van Dort and H. Boelens, in "FLAVOUR '81," ed by P. Schreier, Walter de Grüyter \& Co., Berlin, 1981, pp. 417-431.

23) T. P. Labuza, S. R. Tannembaum and M. Karel, Food Technol., 24, 543 (1970).

24) K. Eichner and M. Karel, J. Agric. Food Chem., 20, 218 (1972).

25) A. Arnoldi, C. Arnoldi, O. Baldi and A. Griffini, $J$. Agric. Food Chem., 35, 1035 (1987).

26) J. Davidek and J. Jiroušovà, Z. Lebens. Unters.Forsch., 159, 153 (1975).

27) J. Pokorny', W. Janitz, I. Viden, J. Velišek, H. 
Valentovà and J. Davidek, Die Nahrung, 31, 63 (1987).

28) M. Sakaguchi and T. Shibamoto, J. Agric. Food Chem., 26, 1179 (1978).

29) F. Ledl and Th. Severin, Chim. Mikrobiol. Technol.
Lebensm., 2, 155 (1973).

30) F. Ledl, Z. Lebensm. Unters.-Forsch., 161, 125 (1976).

31) M. Fujimaki, S. Kato and T. Kurata, Agric. Biol. Chem., 33, 1144 (1969).

32) M. P. Schubert, J. Biol. Chem., 114, 341 (1936). 